\title{
Uso da Ferramenta Computacional GCompris para Auxílio ao Processo de Ensino Aprendizagem do Ensino Fundamental
}

\author{
Gustavo Quaresma da Silva ${ }^{1}$, Aline Montenegro Leal Silva ${ }^{1}$, Francisco Alysson da Silva \\ Sousa $^{1}$, Keylla Maria de Sá Urtiga Aita ${ }^{1}$, Francisco Renato Lima ${ }^{1}$, Vinícius Ponte \\ Machado ${ }^{1}$ \\ ${ }^{1}$ Universidade Federal do Piauí (UFPI) \\ Centro de Educação Aberta e a Distância (CEAD) \\ Curso de Licenciatura em Computação
gustavoquaresma2014@gmail.com, alineleal@ufpi.edu.br webalysson@ufpi.edu.br, keyllaurtiga@ufpi.edu.br, fcorenatolima@hotmail.com, viniciuseufpi.edu.br

\begin{abstract}
One of the main challenges of current education is the insertion of information and communication technologies as a way to improve the teachinglearning process. Computational tools can assist the teacher and student when developing their activities inside and outside the classroom. This work aims to analyze the use of the computational tool GCompris in the Lilásia Lobão Marques School Unit in the city of União (Piaui) for elementary school students, as a support to the knowledge construction process. The digital inclusion of children to technological knowledge and learning in a playful way was verified through the GCompris tool.
\end{abstract}

Resumo. Um dos principais desafios da educação atual é a inserção das tecnologias de informação e comunicação como forma de melhorar o processo de ensino aprendizagem. As ferramentas computacionais podem auxiliar o professor e aluno na hora de desenvolver suas atividades dentro e fora de sala de aula. Esse trabalho tem como objetivo analisar o uso da ferramenta computacional GCompris na Unidade Escolar Lilásia Lobão Marques do município de União (Piaui) para alunos do ensino fundamental, como suporte ao processo de construção do conhecimento. Constatouse a inclusão digital de crianças ao conhecimento tecnológico e à aprendizagem de forma lúdica por meio da ferramenta GCompris.

\section{Introdução}

Entre as opções tecnológicas e pedagógicas, o GCompris é um programa educativo de código aberto que muito contribui para a educação. Com a utilização do GCompris podem-se abordar áreas do conhecimento, como Matemática, Ciências, Geografia, Artes e Linguagem, de forma interativa, criativa e em diferentes níveis, para que a criança possa entrar em contato com a linguagem oral, visual e auditiva e com variados usos sociais da leitura e da escrita [Souza 2016].

O estímulo ao uso de softwares educacionais e pedagógicos cresce a cada dia na intenção de proporcionar aos estudantes qualidade de ensino e facilidade no aprendizado educacional, onde o lúdico ganha espaço no ensino-aprendizagem, além de contribuir para que os alunos adquiram novos conhecimentos. O GCompris é um exemplo notável de software livre que possui atividades de cunho educacional com a finalidade de contribuir para o processo de aprendizagem, tornando-o mais prazeroso e contribuindo como suporte ao meio educacional.

O GCompris não está vinculado a orientações curriculares de um país específico, apesar de estar disponível em mais de 50 idiomas e ter como principal público crianças na faixa de 2 a 10 anos. Fica a critério do professor utilizar as atividades de acordo com os objetivos educacionais estabelecidos por eles. Além de possuir atividades relacionadas ao currículo escolar tais como Ciências, Matemática, Letramento, há também atividades que propõem 
auxiliar o aluno no meio digital, estimulando o aprendizado sobre o uso de periféricos como o mouse e teclado entre outras atividades.

As versões para Linux e Mac OS X são gratuitas. A versão para Windows existe em duas modalidades, uma gratuita que permite utilizar apenas algumas das atividades e outra com todas as atividades disponíveis. Nascimento (2017) menciona que a diversidade de atividades e de jogos do GCompris torna-o versátil, no que diz respeito ao atendimento das demandas educacionais e permite que professores e alunos utilizem uma gama de possibilidades em diferentes áreas do conhecimento.

Diante desta realidade, tomou-se a iniciativa de se realizar um trabalho voltado à inserção de alunos do ensino fundamental ao mundo da tecnologia, por meio da ferramenta GCompris, com o objetivo de possibilitar a inclusão digital de crianças ao conhecimento tecnológico e à aprendizagem de forma lúdica. Para tanto, a aplicação deste trabalho se deu, inicialmente, por uma sondagem na escola, fazendo uma análise da realidade. A execução se deu de modo remoto, devido à realidade de pandemia em que nos encontramos. Assim, a explanação sobre o uso da ferramenta foi feita por meio de aplicativos de transmissão de conteúdo, compartilhamentos de arquivos digitais e links.

Este artigo tem como objetivo geral analisar o uso da ferramenta computacional GCompris na Unidade Escolar Unidade Escolar Lilásia Lobão Marques do município de União (Piauí), para alunos do $4^{\circ}$ ano do ensino fundamental, como suporte ao processo de construção do conhecimento. Para tal, pôde-se explorar os jogos contidos na ferramenta de maneira orientada e verificar a sua importância para o processo de ensino-aprendizagem.

\section{Referencial Teórico}

Frente à situação atual de exclusão digital de crianças da cidade de União (Piauí), a sociedade tem a responsabilidade de promover a este público em desenvolvimento, o acesso à tecnologia através de ações que envolvam alternativas técnicas e economicamente viáveis, tais como a utilização de Software Livre.

De acordo com Araújo (2015) os softwares educativos foram criados para uso no processo educacional, garantindo a inserção em contextos de ensino-aprendizagem. Os programas utilizados em processos escolares, em contextos pedagógicos, são tidos como softwares educacionais. O uso adequado oportuniza a habilidade de resolver problemas, o gerenciamento da informação, a habilidade de investigação, aproximação entre teoria e prática e outros.

Pontes (2019) afirma que as Tecnologias da Informação e Comunicação (TICs) são uma necessidade mundial. Nesse entendimento, as instituições de ensino precisam preparar o aluno para essa nova realidade, buscando práticas com o intuito de formar melhor. Nessa discussão, a temática da inclusão digital apresenta-se como de grande importância, pois a educação dos novos tempos deve ser pensada no sentido de tocar a vida das pessoas, favorecendo a construção de uma visão crítica e de emancipação do mundo que nos rodeia e não tão somente na geração de números quantitativos. Igualmente, os bons usos das TICs são valiosas vias didáticas no processo de aprendizagem de alunos e de educadores, ambos interagindo em ações concretas como protagonistas e produtores de saberes [Oliveira 2019].

A inserção das Tecnologias de Informação e Comunicação na escola precisam ser acompanhadas por uma metodologia que satisfaça as necessidades dos alunos, utilizando adequadamente e significativamente, questionando o objetivo que se pretende atingir [Araújo 2015]. O crescente interesse de inserção da informática educativa pela comunidade acadêmica e científica, visando aumentar a motivação e engajamento dos estudantes no processo de 
aprendizagem, tem despertado a atenção de pesquisadores da área de informática na Educação para o desenvolvimento de recursos digitais e modelos para auxiliar o professor na sala de aula [Reinoso et al. 2017].

As ferramentas digitais se tornaram uma aliada ao processo de ensino e aprendizagem, sobretudo nas disciplinas que demandam conhecimento em matemática. Assim, os projetos que objetivam incentivar as tecnologias são de grande importância para um ensino conectado com a realidade do século XXI [Silva 2019].

Alguns aplicativos se destacam devido a diversificação de atividades, habilidades exigidas pelos usuários, condição aos educandos. $\mathrm{O}$ impacto destes aplicativos no processo de ensino, em um primeiro momento, se dá pela posição do aluno como sujeito ativo, que pode desenvolver habilidades, interpretar e interagir. Isso pode ser realizado de uma forma dialógica e comprometida com a informação e o conhecimento [Stürmer 2019].

O software educativo é um recurso tecnológico que pode ser trabalhado em qualquer disciplina escolar e pode ser encontrado nas áreas de Língua Portuguesa, Matemática, Biologia e Química. Entre esses programas educativos, o GCompris se apresenta como um excelente recurso, pois é um programa de código aberto, disponível sob a licença General Public License (GNU). Lançado em 2000 pelo francês Bruno Coudoin, ele é composto de 107 atividades lúdicas, dirigido a crianças entre 2 e 10 anos de idade [Araújo 2015].

Conforme Araújo (2015), o GCompris pode ser trabalhado em diversas atividades, disciplinas e séries, da educação infantil até a quarta série. Os jogos vêm com um objetivo específico. Assim, pode-se deixar a criança livre para navegar e escolher os jogos que achar mais interessantes, desenvolvendo assim uma capacidade de escolha e aprendizagem. Apesar dos relatos recentes de aplicação das TICs na primeira etapa da Educação Básica [Machado, Warpechowski e Vaz 2017], o uso efetivo da informática educativa no contexto da educação infantil ainda é um grande desafio no cenário brasileiro.

GCompris é um programa com inúmeras possibilidades e estratégias que disponibiliza atividades pedagógicas que podem ser trabalhadas de modo lúdico, contribuindo para o desenvolvimento de raciocínio lógico, coordenação motora, dentre outros. Além disso, ainda contribui para que o aluno aprenda e desenvolva habilidades em utilizar o computador. O uso do software GCompris eleva a qualidade da aprendizagem e contribui na aquisição de novos conhecimentos. [Guedes, Brito e Gomes 2016]

\section{Metodologia}

A evolução desta pesquisa se deu através de 6 fases (Figura 1). Inicialmente foi realizada uma revisão bibliográfica de artigos científicos sobre o tema na Internet e em seguida um estudo da ferramenta GCompris foi realizado com a finalidade de aplicá-la na Unidade Escolar Lilásia Lobão Marques do município de União (Piauí). Todo esse estudo fundamentou-se em uma perspectiva qualitativa e interativa, em que cada aluno foi interagindo com o aplicativo.

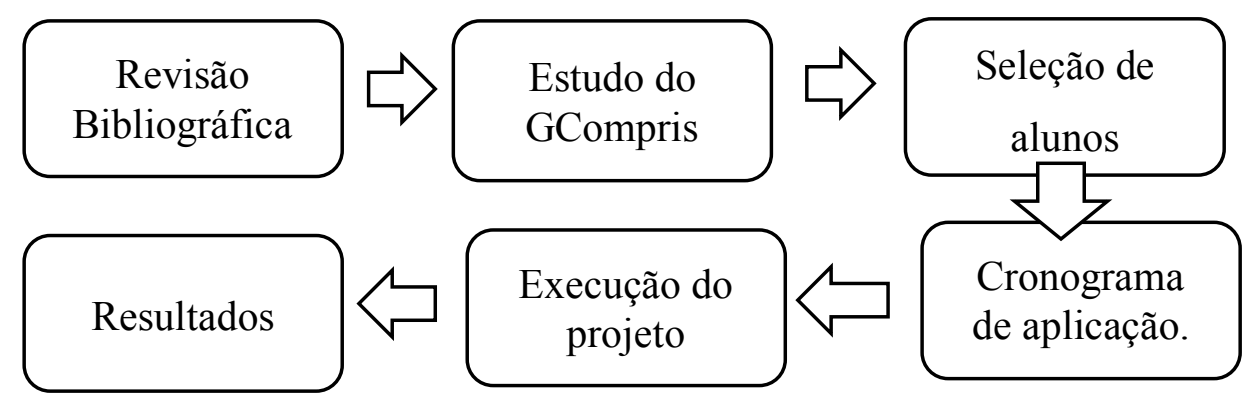

Figura 1: Fluxograma da metodologia. 
Em seguida a fase de estudo partiu-se para a seleção dos alunos, cujo requisito era escolher entre eles os que tinham condições de interação com a ferramenta através do smartphone, bem como capacidade de receber e executar instruções sobre a utilização do software educacional. Após isto, escolheu-se como público-alvo, alunos da Unidade Escolar Lilásia Lobão Marques, especificamente do $4^{\circ}$ Ano do Ensino Fundamental, que possuem entre 9 e 10 anos de idade. A série escolhida foi em função de haver uma quantidade grande de jogos na ferramenta destinados a essa faixa etária, além de vários alunos dessa série possuírem uma deficiência cognitiva. A escola é da rede pública municipal e tem como clientela alunos de realidade carente.

Aplicada de forma remota devido à pandemia do Coronavírus, o estudo da ferramenta se deu por um período de 12 dias para os alunos envolvidos na pesquisa utilizarem a ferramenta, visando a obtenção do conhecimento necessário para a aplicação posterior do questionário remoto, além de almejar melhorias nas desenvolturas cognitivas das crianças, tais como: o desenvolvimento nos aspectos linguístico, cognitivo, social, moral, afetivo, atenção, concentração e coordenação motora.

Para o resultado final, foi elaborado um questionário sobre o uso da ferramenta, o qual foi respondido pelos alunos e professora titular da série, de modo que fosse possível avaliar os impactos do uso dessa ferramenta. As orientações do uso do aplicativo se deu através de um grupo de Whatsapp criado pela escola para acompanhar as aulas remotas, onde os alunos puderam conhecer um pouco mais sobre a ferramenta e como utilizá-la. Logo após as principais orientações os alunos começaram a utilizar a ferramenta e foi gerado na plataforma Google Forms um link com as perguntas a respeito do aplicativo com 06 perguntas para os alunos no qual foi possível obter as respostas para tabulação de dados.

Hoje em dia as ferramentas computacionais fazem parte da vida das pessoas em todos os contextos sociais e os alunos são os que mais usufruem delas por meio do uso de aplicativos de bate papo e redes sociais, levando em consideração o conhecimento de mundo que o aluno já possui ao ingressar na vida escolar. Porém, o que tem se identificado décadas após décadas são as dificuldades encontradas pelos alunos na resolução de atividades que se referem a certas disciplinas.

A Figura 2 apresenta a página principal do GCompris, quando o programa é iniciado e apresenta uma interface gráfica com uma lista de atividades centrada no lado esquerdo e uma barra de controle na parte inferior.

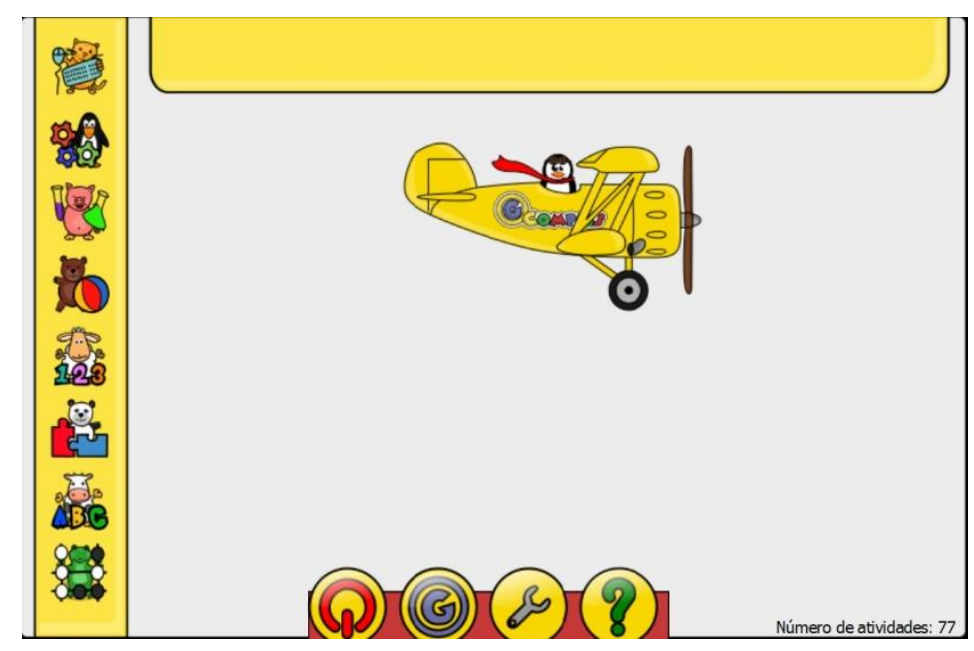

Figura 2: Tela inicial da ferramenta GCompris. 
Deste modo, o GCompris consiste em um conjunto de atividades de cunho educacional com a finalidade de tornar o processo de aprendizagem mais lúdico e produtivo no meio escolar e na vivência do aluno (Tabela 1). Para a execução da ferramenta, penúltima fase do experimento, foi utilizada uma série de jogos desenvolvidos no GCompris.

Tabela 1. Categoria de atividades da ferramenta GCompris.

\begin{tabular}{l|l}
\hline \multicolumn{2}{l}{ Categoria de Atividades GCompris } \\
\hline $\begin{array}{l}\text { Descoberta das partes do } \\
\text { computador }\end{array}$ & Teclado, mouse, touchscreen.... \\
\hline Leitura & Letras, palavras, práticas de leitura, digitação de texto \\
\hline Aritmética & $\begin{array}{l}\text { Operações com números, memorização de tabelas, } \\
\text { enumeração,.... }\end{array}$ \\
\hline Ciências & Controle do canal, ciclo da água, energia renovável,... \\
\hline Geografia & Países, regiões, cultura,... \\
\hline Jogos & Xadrez, memória, ligue 4, jogo da velha,... \\
\hline Diversos & Cores, formas, braile, aprenda a dizer a horas,... \\
\hline
\end{tabular}

Assim, diante da tabela acima, podemos perceber que o GCompris possui uma série de características que o torna uma ferramenta educacional que contempla diversas áreas do conhecimento educacional, além de possuir ferramentas livres que não geram custos ao ser adotado nas redes de ensino.

Ao final da experiência foi utilizada como instrumento de fechamento do experimento, um pequeno questionário respondido pelos alunos e pela professora titular da série, como forma de avaliar se o aplicativo é de fácil manuseio e se promove realmente a aprendizagem.

\section{Resultados e Discussões}

Nesta sessão, apresentou-se os resultados desse trabalho. Para isso, realizou-se um questionário com 6 perguntas para seis alunos e 4 perguntas para a professora titular a respeito dos jogos, por meio de um link gerado pela plataforma Google Forms e enviado aos alunos e à professora por meio do grupo da escola após a utilização da ferramenta computacional. Dando continuidade, realizou-se a tabulação dos dados após o retorno do questionário respondido.

A primeira pergunta do questionário buscava saber se os alunos já haviam tido algum contato com o Software GCompris. Assim, 42,9\% da turma afirmou que não, enquanto 57,1\% apresentou que sim (Figura 3). Coudoin (2011) destacou que a comunidade que interage com o projeto é ativa, revelando 1.000 visitas diárias à página principal, o que significa uma relevante inserção do software na educação.

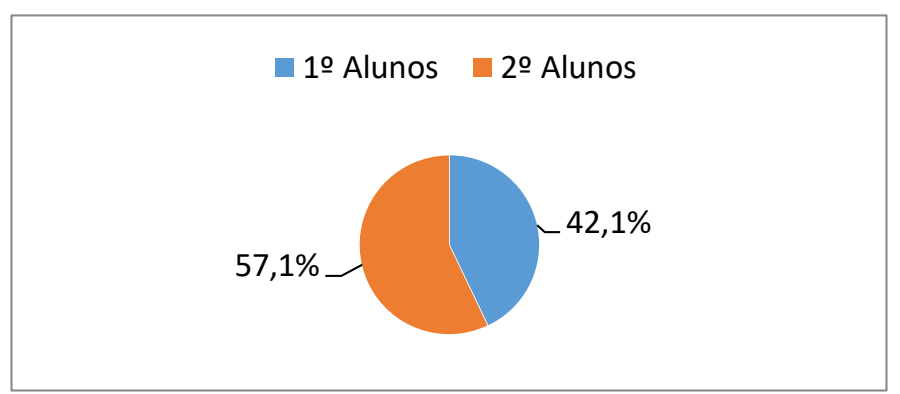

Figura 3: Contato anterior com a ferramenta. 
Na segunda pergunta do questionário, foi indagado se a linguagem do Software é de fácil acesso e como resultado $85,7 \%$ dos envolvidos nessa pesquisa apontaram-na como de fácil compreensão, enquanto 14,3\% apontaram como não tão compreensível (Figura 4). Oliveira (2019) afirma que o uso software é fácil, devido à sua interface, que apresenta uma visão clara e simples, possibilitando uma melhor compreensão por parte de quem o usa.

Entretanto, mesmo a maioria dos alunos tendo considerado essa ferramenta de fácil compreensão, 85,7\%, também apresentaram a sala de aula como o meio mais fácil de apreender Matemática, enquanto 14,3\% optou pelo computador para o aprendizado, por meio da pergunta de número 3 do questionário. Assim, pode-se inferir que as ferramentas digitais educativas são recursos que podem auxiliar o trabalho docente, porém não conseguem substituir o papel do professor e da sala de aula.

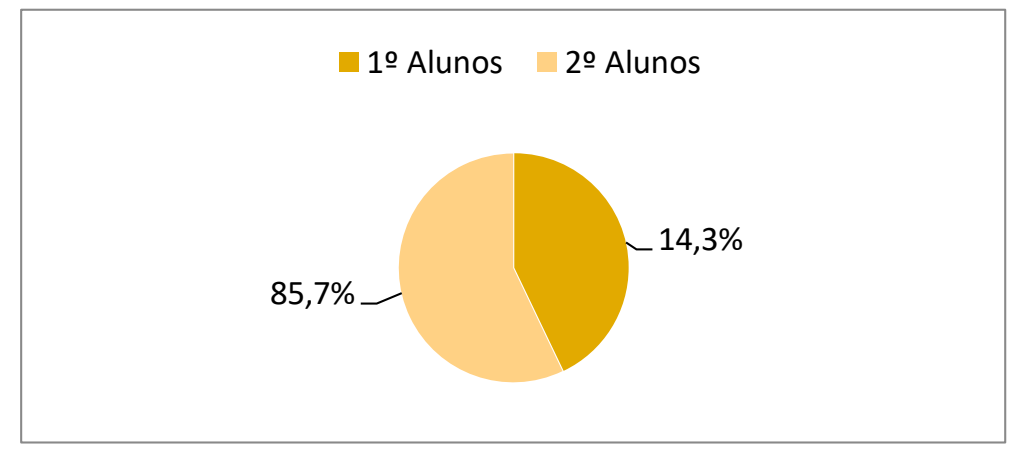

Figura 4: Quanto a linguagem.

Quando foi indagado sobre a qualidade das imagens do software, 83,3\% afirmaram contribuir para aprendizagem e construção do conhecimento e 16,7\% acreditaram não contribuir (Figura 5). Pedrosa (2003) postula que os menus com tons de cores classificáveis como fortes e vivas atrai a atenção focal do usuário. Entretanto, pode também deixá-lo fatigado se a exposição for excessiva: em grandes áreas e por um período prolongado de tempo.

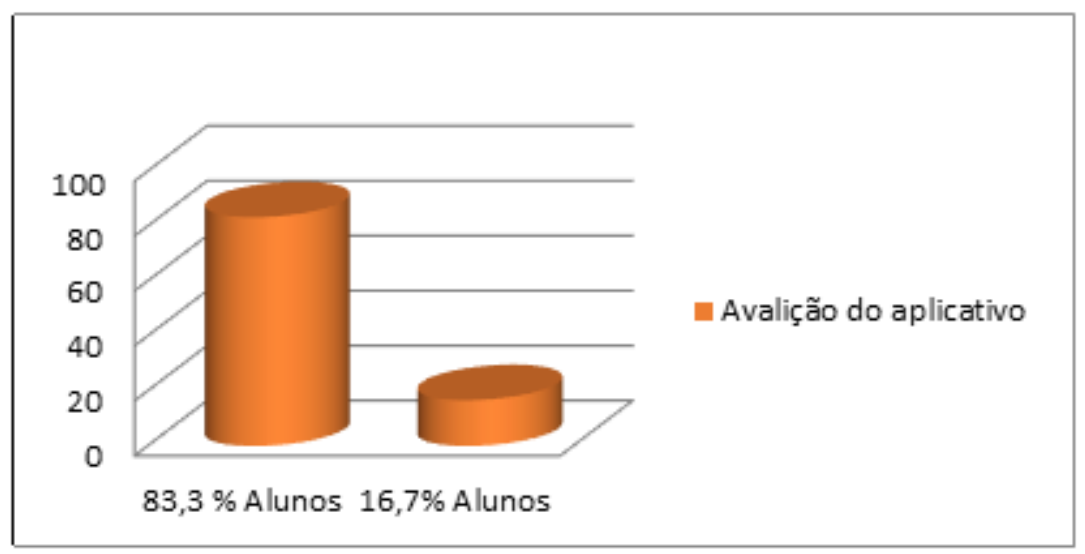

Figura 5: Avaliação do aplicativo.

Quando se perguntou sobre o fator manter a atenção e motivação para estudo, 85,7\% se manifestaram de forma positiva e 14,3\%, de maneira negativa (Figura 6). Os resultados deste trabalho corroboraram com o que a literatura aponta sobre o GCompris e seu alto fator de contribuição para a educação, por ser acessível, de fácil uso e de grande potencial interativo e atrativo. 


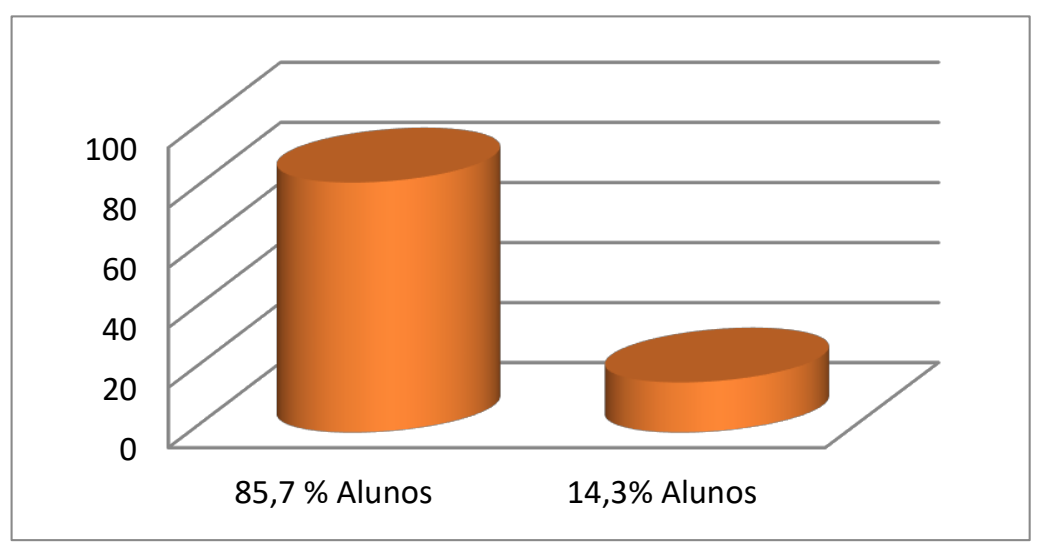

Figura 6: Interação com o aplicativo.

Além das cores, como já fora dito, as músicas e efeitos sonoros são um outro fator positivo, pois atraem a atenção do usuário em relação ao software. Com o uso da música de fundo e efeitos sonoros, gera-se emoção ao usuário, que influenciará em suas ações, estado mental e expressões, além de estimular situações de velocidade, paciência, estado de urgência, entre outros [Ekman 2008].

A respeito das 4 perguntas feitas à docente titular da série, concluiu-se que, segundo a visão da professora, o aplicativo pode sim ser bastante útil dentro de sala de aula e que ele se mostrou uma ferramenta muito importante para o processo de ensino-aprendizagem.

\section{Conclusão}

Conclui-se que o uso de softwares educacionais tais como GCompris, como recurso didático no ensino fundamental, tem se alicerçado como uma necessidade no ensino básico, sendo uma importante ferramenta educacional. Contudo é de suma importância, por parte das autoridades do poder público, investimentos na capacitação dos professores para o melhor manuseio da ferramenta computacional e na construção de espaços e compra de equipamentos tecnológicos que venham a contribuir para inclusão digital e para o uso de tecnologias como recurso didático no ensino e aprendizagem.

Por meio da realização deste trabalho pretende-se, em um futuro próximo, que seja inserido nas instituições do ensino básico do município de União (Piauí), o uso de ferramentas computacionais como GCompris para auxílio às aulas e para o melhor progresso dos alunos dentro e fora da escola. Foi muito gratificante orientar e mostrar para os alunos e professores que novas formas de ensino podem ser trabalhadas no ambiente escolar com auxílio do professor.

\section{Referências}

Araújo, L. C. (2015). O uso do software educativo GCompris no ensino da matemática nas séries iniciais do ensino fundamental. Universidade Federal Rural Da Amazônia, Marabá, PA, 2015.

Brandalise, M. A. T. (2019). Tecnologias de informação e comunicação nas escolas públicas paranaenses: avaliação de uma política educacional em ação. EDUR • Educação em Revista. 2019; 35:e206349

Coudoin, B. (2011). GCompris. Em: GCompris. http://GCompris.net. Julho. 
Ekman, I. (2008). Psychologically Motivated Techniques for Emotional Sound in Computer Games", Em: AudioMostly 2008. pg. 20-26. October, Piteå, Sweden.

Guedes, A. M.; Brito, J. A. Gomes, R. A. (2016). Contribuições do uso do software GCompris na educação de jovens e adultos. Sánchez, J. (2016) Editor. Nuevas Ideas en Informática Educativa, V. 12, p. 378 - 382. Santiago de Chile

Oliveira, A. S. (2019). Notas sobre inclusão digital no espaço escolar à luz dos usos dos memes. Periferia, v. 11, n. 1, p. 214-230, jan./abr.

Oliveira, F. J. (2019). O uso de jogos educacionais nas escolas: uma abordagem sobre o GCompris. UFPB. Repositório Institucional da UFPB UFPB - Campus IV - Centro de Ciências Aplicadas e Educação (CCAE) CCAE - Trabalhos de Conclusão de Curso de Graduação TCC - Ciência da Computação - CCAE

Pedrosa, I. (2003) “O Universo da cor”. Senac. $1^{\circ}$ ed. 160p. São Paulo.

Pontes, D. M. C. R. (2019). O uso de tecnologias educacionais nas escolas dos anos iniciais da cidade de Parnamirim-RN. UFRN, Natal, RN, 2019.

Machado, D., Warpechowski, M., \& Vaz, D. (2017). Modelo de Interação Entre Pares (MIP): viabilizando o ensino da informática educativa na Educação Infantil. In: Anais do Workshop de Informática na Escola (Vol. 23, No. 1, p. 353).

Nascimento, C.A. (2017). O Uso do Software GCompris Como Ferramenta Pedagógica no Processo de Ensino e Aprendizagem em uma Perspectiva Inclusiva. Dissertação (Mestra do em Educação). Universidade de Brasília, 2017. Disponível em:http://repositorio.unb.br/handle/10482/31702.Acessoem:13mai.2019.

Reinoso, L., Amorim, M., Tavares, O., \& Almeida, R. (2017). Framework CAP 1.0 para criação e uso de arquiteturas pedagógicas. In Brazilian Symposium on Computers in Education (Simpósio Brasileiro de Informática na Educação - SBIE) (Vol. 28, No. 1, p. 384).

Silva, M. T. (2019). Avaliação do uso do software educacional GCompris: uma abordagem da interação humano-computador para o ensino e aprendizagem da matemática no ensino fundamental em uma escola pública de castanhal/PA. Faculdade de Computação. Universidade Federal do Pará, Castanhal-PA, 2019.

Souza, C. G. D. (2016). Formação Continuada de Professores: incentivando a utilização do software GCompris em sala de aula. Dissertação (Mestrado Acadêmico em Ensino). Centro Universitário Univates. Lajeado, 2016. Disponível em: https:/www.univates.br/bdu/bitstream/10737/1140/1/2016 Carmem Gorete Duarte de Souza. Acesso em: 13 maio 2019.

Stürmer, A. B (2019). Análise do software GCompris como recurso educacional para o Ensino Fundamental. Revista Temática. Campinhas, a. XV. N. 12. Dez. 2019. 